\title{
Coaching in design-based learning: a grounded theory approach to create a theoretical model and practical propositions
}

\author{
M. R. van Diggelen ${ }^{1,2}$ (D) K. I. Doulougeri ${ }^{2}$-S. M. Gomez-Puente ${ }^{2} \cdot$ G. Bombaerts ${ }^{2}$. \\ K. J. H. Dirkx ${ }^{1}$. R. J. A. Kamp ${ }^{2}$
}

Accepted: 4 October 2019 / Published online: 6 November 2019

(C) The Author(s) 2019

\begin{abstract}
The purpose of this study is to determine what good coaching during design-based learning (DBL) entails by integrating theoretical and practical perspectives on good coaching. For this purpose, a grounded theory approach was used. For the practical perspective, themes on good coaching were derived from a qualitative study on coaching by observing and interviewing teachers and students involved in a DBL project. For the theoretical perspective, we consulted and analyzed literature on scaffolding, feedback, and formative assessment and coaching in problem-based learning from the learning sciences and the studio model from arts and design literature. Synthesizing themes from both perspectives led to the development of a theoretical coaching model consisting of three main categories (and four subcategories), seventeen themes and thirteen propositions. The model and propositions might be of use for those involved in coaching students in DBL and provide relevant directions for research on coaching in DBL.
\end{abstract}

Keywords Inductive teaching · Design-based learning $\cdot$ Coaching $\cdot$ Creativity and innovation $\cdot$ Higher education

\section{Introduction}

Globally, technological universities aim to educate the engineer of the future whom should be able to deal with complex design challenges in a multidisciplinary setting. This requires creative and innovative thinking and design skills. Scholars argue that-in order to achieve that goal-engineering education needs to adopt an inductive approach to teaching and learning and leave behind its classical educational models (Prince and Felder 2006). Design-based learning (DBL) is seen as a powerful inductive teaching method to support students in becoming creative and innovative thinkers

M. R. van Diggelen

migchiel.vandiggelen@ou.nl

1 Open University of the Netherlands, Heerlen, The Netherlands

2 Eindhoven University of Technology, Eindhoven, The Netherlands 
and to develop associated and relevant skills (Gomez-Puente et al. 2013) and is an educational approach commonly used to foster students' design thinking (Gomez-Puente et al. 2013). DBL can be defined as an educational approach funded in processes of inquiry, reasoning and making for the purpose of creating innovative artifacts, systems and solutions for design challenges as engineers and scientists do (Gomez-Puente et al. 2013).

DBL in higher education is still an underexplored area of research. Only recently, DBL has been characterized in the context of Higher Education (e.g., Gomez-Puente et al. 2013). In this study we focus on the role of the coach who has the responsibility to monitor and, if needed, support and/or challenge students motivation, learning progress and quality of work (Hmelo-Silver and Barrows 2006). The coach strongly affects what students learn from DBL and how they perceive it. Coaching, though, is for many scientists a complex skill (Hmelo-Silver et al. 2019). They are oftentimes not educated to coach. Consequently, many teachers shape their coaching based on experience, intuition, and common sense (Savin-Baden 2003). As a result, there is an urgent need to inform teachers-from now on referred to as coaches-about evidencebased principles of good coaching. Unfortunately, the literature on coaching in DBL in higher education is limited. Consequently, to date, there is little empirical and knowledge available to inform policy makers, curriculum developers, and teachers working in DBL settings on how to coach (Razzouk and Shute 2012).

An underlying problem is a lack of theories available to inform coaches and other stakeholders on how to coach students in a DBL context. In their review, authors (Gomez-Puente et al. 2013) concluded that good coaching perspectives are oftentimes based on general learning science literature. Far less literature is available on coaching in design education or combining both kinds of literature. We view both streams of literature as complementary. Against this background, we conducted a grounded theory approach to answer the following research question:

What does good coaching in DBL entail?

This paper has two objectives. The first aim is to construct a theoretical model of good coaching practices in DBL. The model will be developed by combining observational data, interviews to include a practical perspective on good coaching in DBL and a literature review to add the theoretical perspective on coaching in DBL. A second aim is then to formulate practical propositions on how to achieve good coaching in DBL.

\section{Method and materials}

\section{Design}

To answer our research questions, we undertook a grounded theory approach (GTA). Through simultaneous data collection, analysis and synthesis, GTA enables the construction of a theory grounded in the collected data (Bryant and Charmaz 2007). To assure grounding of the data the constant comparative method was used (Dunne 2011). This involves breaking down the data into discrete units and coding them to categories (Glaser and Strauss 2017). The researcher uses provisional theoretical ideas to decide what data 


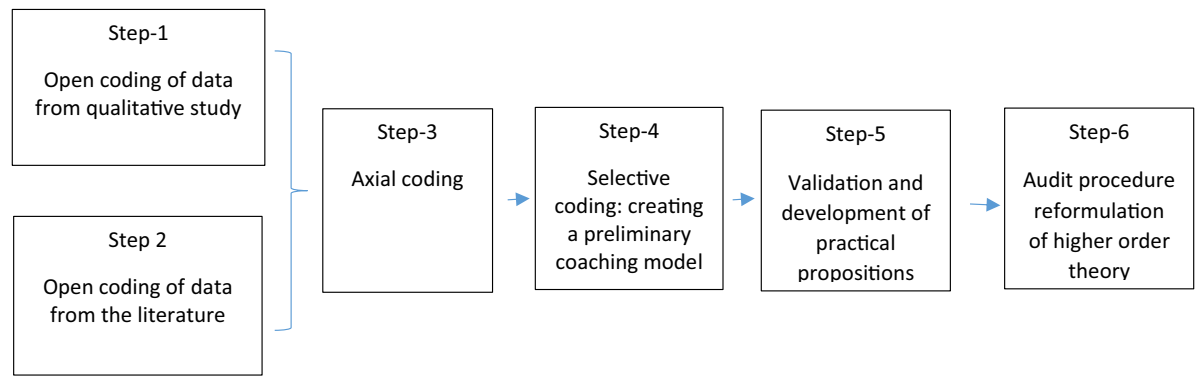

Fig. 1 Overview of steps taken to develop the coaching propositions

will be collected in the next step and where this data can be found. In this way, questions that come up during the analysis and reflection on the data can be answered.

\section{Data-collection and analysis}

The GTA consisted of a process of comparison, analysis and reflection repeated several times according to a predefined plan of several steps until theoretical saturation was reached. Figure 1, provides an overview of these steps which were often performed in parallel.

During each step, comparisons were made. Step 1 and 2 were performed in parallel and used for open coding of data derived in the qualitative study and the literature study phase.

\section{Step 1: qualitative study}

The qualitative case study was conducted to include practical perspectives on coaching in DBL. The study was performed in the context of a design based learning project.

Description of DBL project course context The course is an DBL project course wherein second-and third year Bachelor Students from different Engineering disciplines work on an open, multidisciplinary and authentic design challenge to create a robot design. The course is provided by a team of highly engaged and motivated coaches from several Engineering disciplines. The course lasts 10 weeks and is provided four times per academic year. After an introductory lecture in the first week and until the assessment in the final week, students receive coaching sessions for half an hour. For each coach session, the student team is expected to update its wiki-page. During these coaching sessions all students are present and also all coaches participate to discuss where students are in their design project, where they would like or need to go and how the students can get there.

Data collection During four quartiles, data was collected through interviews with students, coaches, observations of coach dialogues between the coaches and groups of students and analyzing the written reflections of students published on their wiki-page. In 2017, 11 group interviews were conducted; in every interview 3-4 students participated. Two researchers conducted frequent classroom observations and discussions with the teachers were con- 
ducted at least 4 times during the 4 quartiles. In 201825 groups provided written reflections on the progress of their project and their perception of coaching on a weekly basis for 5 weeks.

\section{Step 2: literature review}

To include the theoretical perspective on coaching in DBL, we consulted and analyzed literature on scaffolding, feedback, formative assessment and coaching in problembased learning from the learning sciences and the studio model from arts and design literature. The intend was to include articles that (a) contributed to getting an adequate, but not exhaustive, overview of how the concept is described in literature, and (b) were informative for coaching in DBL. Google scholar was used to find literature on coaching in design. We searched with the words coaching, innovation, creation, and design and coaching and problem-based learning. Once useful articles were selected, their reference list was screened for further articles and articles citing the primary article were also considered.

\section{Step 3-6: data analysis and synthesis into one theoretical model}

Two researchers aimed to identify, name, categorize, and describe phenomena in the data from the qualitative study and the literature review and to identify additional routes for data collection. In this phase, comparisons were made within the different data sources of the qualitative study and within the literature related to a concept. All meaningful data that related to the research question was coded to develop an initial list of themes of good coaching in DBL. This resulted in 15 themes in total and two lists of preliminary themes: one list for the qualitative study ( 8 themes) and one list for literature study ( 7 themes). The lists with initial themes were discussed with two more researchers involved in the study.

In step 3 the axial coding step, two researchers aimed to identify relations between the different sources of data in order to form more abstract codes. The models from both the theory and the qualitative study were compared to allow the emergence of a single shared coaching-model containing themes that were found, either explicitly or implicitly, in both data sources. After comparing themes from the qualitative data with themes derived from the theoretical review 9 themes were found in both sources, 2 themes were only present in the qualitative funded model and 4 themes were only present in the theoretical funded model. Constant comparison was also used to recode the consulted literature. This additional (re)coding stage resulted in the following: (a) themes that had a very specific and overly narrow definition were merged with a related theme and were given a broader definition that included both; and (b) themes that were overly broad in definition and those that seemed to encompass two distinct themes were split up. Again, the results of this step performed by two researchers were discussed with two other researchers. In this step, the sixteenth theme 'coaching literacy' was added based on the recoding of the literature.

Step 4 was the selective coding phase to compose a preliminary theory. The aim was to (a) relate all themes, and (b) outline how these themes were related to the concept of coaching in DBL. The GTA methodology was also used in this step (Charmaz 2006). The essential idea was to develop a single higher-order theory as a storyline around 
which the themes are built. To do so, it was examined to what extent and how the themes were related and how the 8 themes present in only the qualitative study or the literature review were related. As a result, we formulated six higher-order categories. Progressing through step 1-4, the comparisons made increased in complexity or amount of data, diversity (different sources of data) and level of analysis (from within data sources to across data sources). During each step, memo-writing was used to stimulate, explicate, and map our reflective process (Charmaz 2006). Memo writing involved writing down thoughts, feelings, or questions that arose from the analytic process (i.e., reflective notes).

In step 5, the preliminary model was validated via an additional round of data collection, to reach theoretical saturation. For that purpose, students were invited to provide written reflections at the end of the course on the key aspects of coaching they found helpful and or challenging/frustrating. Those answers were also analyzed and compared with the initial list of themes. In addition, we conducted observations during the coaching sessions and kept intensive notes. The final set of themes was developed and compared with the themes from the existing data. This led to the inclusion of the seventeenth theme conversation skills. In this step practical propositions, or guidelines on how to coach were also formulated.

In step 6, an audit procedure was organized to improve the trustworthiness of the analysis (Akkerman et al. 2008). The audit procedure was performed by two additional researchers who did not participate in the analysis. Both researchers were provided with context information on the research problem and objectives and were asked to review a document outlining the data-analysis, synthesis of the higher order theory and propositions. The suggestions of the researchers led to an improved version of the coaching model. The themes were used to objectify the model, give more meaning to the categories and clarify what makes the model a higher-order theory. These improvements led to the reformulation of new higher-order categories capturing the old categories: goal-directedness (with four categories), dialogue and environment. Table 1 provides an overview of the themes and categories in the data analysis and synthesis. The final coaching model is presented in the following section.

\section{Results: the coaching model}

The grounded theory approach we undertook to formulate a higher-order theory on coaching in DBL showed us important prerequisites for coaching. Those include: (1) goaldirected coaching (main category one, and its categories designing, design process and thinking, self-regulation and professional identity); (2) the importance of the environment (main category two), and (3) the importance of dialogue between teachers and students (main category three). The model provides an answer to the question "what does good coaching entail".

Figure 2 provides a visual overview of the model. In the remainder of this section, the model is presented. Throughout the section the main categories (MC) and themes (T) are mentioned between brackets to illustrate how they are connected to the claims and/or statements from the higher-order theory. References to literature are only made when an example is provided.

The prerequisites, as mentioned on the previous page, represent the essence of coaching. In this model, coaching is seen as holistic by nature, focusing not only on the goals 


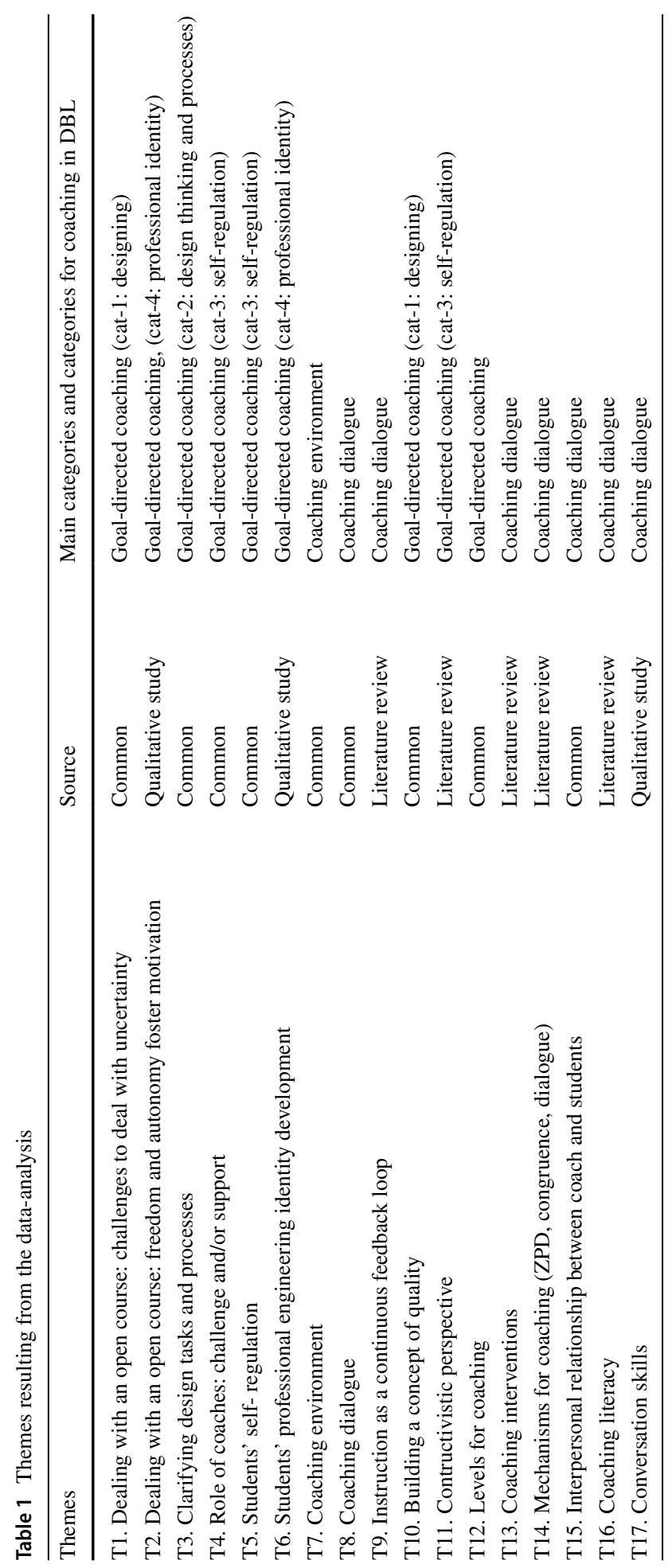




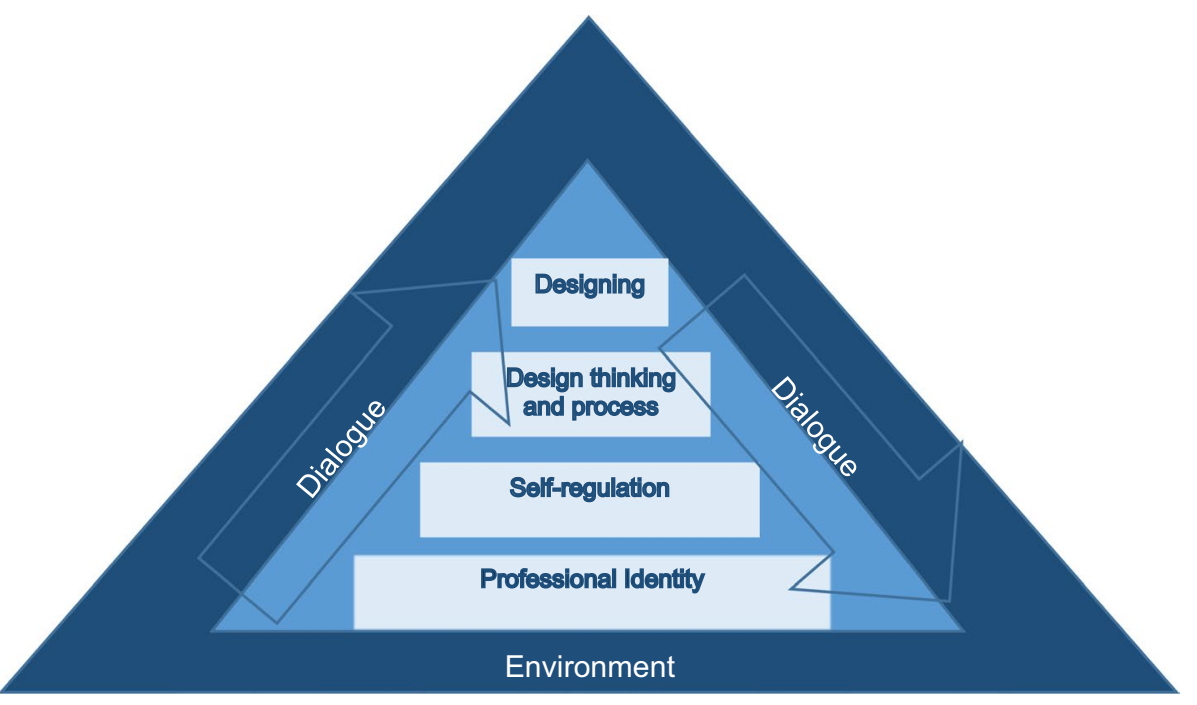

Fig. 2 The coaching model

and content of DBL (MC1; T3-T6; T10-12) but also requiring a supportive and stimulating environment (MC2; T7), that helps students to develop their identity as learners (by helping them to regulate their learning, MC1.3 and MC1.4; T5) and as professionals (by exposing them to a real-life project, MC1.4 and T6) in dialogue with their coach and students (MC3 and T8). The environment, dialogue, and goal-directed coaching mutually influence each other in both a positive and negative way. If a coach, for example, makes use of goal-directed coaching interventions he/she will be better able to direct the attention of the students to the right aspects thereby providing a starting point for a dialogue (Hattie and Timperley 2007; Price et al. 2010; Van Diggelen et al. 2013). The goal-directedness of the interventions will also make the intervention more specific and the intention behind the coaching intervention better understandable for the student which will further facilitate the dialogue (Hattie and Timperley 2007; Van Diggelen et al. 2013). The increased understanding of the student will likely lead to better learning outcomes and more positive perceptions of the environment offered to the coaching. The opposite also holds true. If a coach makes less use of goal-directed coaching interventions, the students' attention is less likely to be directed to the right aspects. Also, the student will perceive the coaching interventions as less specific and experience more difficulties in understanding the intentions or message behind the coaching intervention. Consequently, the student will have a limited understanding of the coaching intervention which may hamper the quality of the dialogue and influence students' perceptions of the environment. Coaching in DBL is, therefore, best seen as a system wherein all factors influence each other. If one element is negatively influenced the flow of the whole coaching system is interrupted and all elements are affected.

Students learning in DBL can be characterized by openness, uncertainty, learning by doing, and learning by mistakes (MC1.1-1.4; T1; T5 and T12). The nature of DBL makes it very personal for students, can be confronting, and can give rise to all kinds of affective responses by students (MC1.1; 1.4; T1; T5 and T6). This may hinder learning to design and also stand in the way of effective coaching (Sawyer 2017, 2018; Schön 1987). Coaching requires students to open up and feel free to express themselves and to dare to learn 
from mistakes (Sawyer 2017, 2018; Schön 1987). It is the challenge for coaches to provide their students with a safe and yet stimulating environment (MC2; T7 and T15). In this context, a dialogue is of utmost importance because it helps to establish a safe and stimulating environment and make coaching effective (MC3). An effective dialogue asks for coaches to help students develop the skills to learn from coaching (MC3, T16), to start a dialogue amongst the project-team (MC3, T11). Moreover, it requires all stakeholders to approach it as a dialogue and a continuous process of questioning where students are in their learning process, where they want to go and how they can get there (MC3 and T9). Coaching is about determining the desired situation, establishing the current situation, observing the gap between the desired and the current situation, determining what is needed to close the gap and actually closing the gap. Dialogue is the modus operandi of good coaching and influences communication between coach and students (MC3 and T15). During a dialogue, a coach can deliberately use different coaching interventions (MC3 and T13), should deliberately pay attention to the communicational aspects of coaching (MC3 and T15) and should adequately apply conversation skills (MC3 and T17) to enable such a dialogue and make coaching goal-directed (MC1 and T12).

Coaching starts with questioning where students are in their learning process and where they want to go thereby establishing their current and desired situation (MC3 and T9). These questions can be answered on different 'levels', namely: designing, design thinking and process, self-regulation and professional identity (MC1.1-1.4; T3-6 and T10-12). Coaching is goal-directed when the interventions deliberately focus on one of the aforementioned levels. The foci can be used to use a sequence of coaching interventions to support and/or challenge students thinking. This sequence of coaching interventions ideally goes upwards or downwards as Fig. 2 indicates where the options of the upward and downward sequence are illustrated by the arrows. The downwards sequence starts from the more concrete and superficial level of the doing, goes to the thinking and the process, makes the bridge to self-regulation and seeks to connect with the more abstract and deeper level of the professional identity. When an abstract and deep professional identity aspect requires translation to the design process the sequence of coaching interventions goes upwards and starts with the level of the professional identity and goes from self-regulation and the design thinking and processes to the designing. Distinguishing and deliberately targeting different foci in coaching helps to differentiate, to direct students' attention and makes the coaching interventions specific.

\section{Propositions for coaching in DBL}

Going one step further from defining what good coaching entails, we present propositions on how to coach. The propositions can be seen as a translation of the higher-order theory on coaching in DBL distinguished in the section on the coaching model. These propositions will be explained based on what we found from studying the practical perspective and/or theoretical perspective on coaching in DBL. In Table 2, below, we provide the coaching categories with their practical propositions. The practical propositions can help coaches to better understand how to ensure that good coaching is implemented. 
Table 2 Coaching model and associated practical propositions

\begin{tabular}{|c|c|}
\hline Coaching model & Propositions on how to coach. Good coaching... \\
\hline Goal-directed coaching (cat-1: designing) & $\begin{array}{l}\text { 1.1.1 Should actively address 'expectation and } \\
\text { learning-outcome-management' }\end{array}$ \\
\hline $\begin{array}{l}\text { Goal-directed coaching (cat-2: design thinking and } \\
\text { process) }\end{array}$ & $\begin{array}{l}\text { 1.2.1 Should constantly stimulate students to } \\
\text { articulate their underlying thinking, the rationale } \\
\text { and how the process is unfolding when they are } \\
\text { generating good work }\end{array}$ \\
\hline \multirow[t]{2}{*}{ Goal-directed coaching (cat-3: self- regulation) } & $\begin{array}{l}\text { 1.3.1 Requires coaches to deliberately constrain the } \\
\text { design process }\end{array}$ \\
\hline & $\begin{array}{l}\text { 1.3.2 Requires exploring and answering where stu- } \\
\text { dents are, would like to go and how to get there }\end{array}$ \\
\hline \multirow[t]{3}{*}{ Goal-directed coaching (cat-4: professional identity) } & $\begin{array}{l}\text { 1.4.1 Requires challenging students to explore their } \\
\text { own PI and (in the long run) develop insight into } \\
\text { the range of existing design conceptualizations }\end{array}$ \\
\hline & $\begin{array}{l}\text { 1.4.2 Requires challenging students to explore a } \\
\text { coach his/her PI and (in the long run) develop } \\
\text { insight into the range of existing design conceptu- } \\
\text { alizations }\end{array}$ \\
\hline & $\begin{array}{l}\text { 1.4.3 Requires relating design activities and pro- } \\
\text { cesses to personal and/or professional experiences } \\
\text { or images of practices }\end{array}$ \\
\hline Coaching environment & 2.1 Requires a safe and stimulating environment \\
\hline \multirow[t]{5}{*}{ Coaching dialogue } & $\begin{array}{l}\text { 3.1 Requires stimulating dialogue amongst the } \\
\text { project team }\end{array}$ \\
\hline & $\begin{array}{l}\text { 3.2 Coaching requires contributing to students } \\
\text { coaching literacy }\end{array}$ \\
\hline & $\begin{array}{l}\text { 3.3 Requires all stakeholders to approach it as a } \\
\text { continuous dialogue }\end{array}$ \\
\hline & $\begin{array}{l}\text { 3.4 Requires a coach to deliberately make use of } \\
\text { coaching interventions }\end{array}$ \\
\hline & $\begin{array}{l}3.5 \text { Requires a coach to adequately apply conversa- } \\
\text { tion skills }\end{array}$ \\
\hline
\end{tabular}

\section{Main category 1.0: goal-directed coaching}

\section{Coaching goal 1.1: designing}

Coaching starts with questioning where students are in their learning process and where they want to go (Black and Wiliam 2009; Hattie and Timperley 2007; Sadler 1989; Ramaprasad 1983). Focusing on designing is about the doing and the making and about the (intermediate) results of the design process. This focus strongly corresponds with what Miller (1990) calls "demos": what is visible. The focus of designing can be used to make implicit thinking processes explicit with reflection on action and linking the making to the thinking (Adams et al. 2003). It can also be about students' intentions or the goals they want to formulate and realize. As becomes clear from the observations in the qualitative study, this focus is often the starting point for coaching in DBL. While designing, it can be used to make the "thinking" explicit and to discover the underlying rationale of the design (Adams et al. 2003, 2016). 
As already stated, coaching interventions are the most effective when they are embedded in what students have done or created in their design process. Coaching will not actively engage students when it does not build on an experience, image, or knowledge students have (Black and Wiliam 2009; Hattie and Timperley 2007; Sadler 1989; Ramaprasad 1983). Ideally, coaching on the design process always starts with something the students have done or thought of (Black and Wiliam 2009; Hattie and Timperley 2007; Sadler 1989; Van Diggelen et al. 2013). If students can't get started coaching starts with finding out what the students were thinking when they got stuck or by describing what happened when they were asked to start designing. A next step in the coaching, then, is to switch to the thinking and process of designing and to continue with self-regulation and professional identity.

Proposition 1.1.1 Coaching requires actively addressing 'expectation and learning-outcome-management'.

In DBL students may work on open and complex design challenges resembling the professional practice engineers will face in their professional career. Solving complex ill-defined challenges implies freedom and places a strong emphasis on students/student teams' self-directedness (Gomez-Puente et al. 2013). In these circumstances, students can easily lose overview and perceive difficulties in finding out what is expected of them (Sawyer 2018). In particular, when students have little experience in undertaking these kind of open projects, they need to deal with issues as openness, little structure, freedom, and responsibility for self-managing the process (Hmelo-Silver 2004; Savin-Baden 2003; Schön 1987). Therefore, it is very important that coaches explain what is expected of the students. These expectations should be related to students experiencing the process, finding their own way, learning by discovery, learning by making mistakes, managing the freedom, ambiguity, and openness to develop a self-directed attitude and developing skills to direct their own process (Adams et al. 2016; Savin-Baden 2003; Sawyer 2018). Students need time and opportunities to get used to DBL and develop the aforementioned aspects (Edström and Kolmos 2014).

\section{Coaching goal 1.2: design thinking and process}

A large part of the design process is not intentional and is done based on intuition and or just by doing (Barron et al. 1998; Hinson 2007). In these instances, students may not consider the impact and consequences of choices. Students often just do (McDonnell 2016; Schank et al. 1999; Waks 2001). Actually, it is learning by doing. So, students need to reflect on and learn from their experiences in order to raise awareness, develop insights and/or to confirm previously developed insights. It is important for students to become aware of their own design approach (Van Dooren et al. 2014; Lousberg et al. 2019). This awareness and reflection on experiences can be used to improve their process and make deliberate decisions (van Dooren et al. 2018; Lousberg et al. 2019). The process of becoming aware of one's design approach and learning from experiences is facilitated by a constant articulation of the underlying thinking processes, rationale, and progress (Adams et al. 2016; Sawyer 2017). It is the challenge for students to re-word what they are thinking when they generate good work (Adams et al. 2016; Sawyer 2017). 
Proposition 1.2.1 Coaching requires constantly stimulating students to articulate their underlying thinking, the rationale and how the process is unfolding when they are generating their work.

\section{Coaching goal 1.3: self-regulation}

As in open projects, student teams need to be self-directive and are supposed to explicate, narrow and structure their own learning and design processes, reflect on the process and regulate or adjust their approach (Brodeur et al. 2002; Dym et al. 2005). Coaching students during these type of projects should always be focused on supporting and challenging them to develop metacognitive knowledge on how they regulate and need to regulate their own design process (Clark 2012; De Graaf and Kolmos 2003). Such knowledge will help the students to apply the gained insights in the next design iteration. Self-regulation is the focus of coaching interventions where coaches intentionally empower students and stimulate students to learn how to act independently (Hattie and Timperley 2007). It is the focus of coaching interventions where coaching helps students to develop feedback literacy (Carless and Boud 2018; Henderson et al. 2019; Sutton 2012). The better students are able to regulate their own design process the fewer constraints a coach will place.

\section{Proposition 1.3.1 Coaching requires deliberate constraint of the design process.}

Students working on DBL have to deal with many different processes in parallel and have to make many decisions during the design process (Razzouk and Shute 2012). Students need to learn to deal with this freedom, to make the right decisions and to manage their process. Setting the right constraints will guide students through the design process and lead them through a process of self-discovery, exploration, experimentation and active learning (Sawyer 2017, 2018). Constraints can, for example, prevent students from following their instincts, start with one of the initial ideas and rush through the process by following this early idea. From the observation in the qualitative study it appeared to be important for coaches to develop insight into the tendencies that students demonstrate when learning to design. Knowledge of these tendencies enables teachers to adequately constrain the design process. An example of constraints a teacher can set are: not to comment on the aesthetics of deliverables to guide students away from a focus on the intended final product (Sawyer 2015). Another example might be that coaches do not provide specific answers because it prevents students from going into the process themselves (Adams et al. 2016; McDonnell 2016; Sawyer 2017). From the reflective writings analyzed during the qualitative study it appeared, constraints can be placed on what students want or are able to learn (e.g. providing several options to choose between), when students learn or undertake a certain activity (e.g. prescribing moments in time were another design iteration needs to take place), and how (e.g. choosing between different design approaches or when making something).

Proposition 1.3.2 Coaching requires exploring and answering where students are, would like to go and how to get there.

Coaching can be seen as a continuous process of finding out where students are, would like to go to and how to get there (Black and Wiliam 2009; Hattie and Timperley 2007; Sadler 1989; Ramaprasad 1983). These activities can be performed by the teacher, a 
student or jointly. The activities a student is unable to perform need to be taken over by the teacher. If a student is able to perform an activity, the teacher only needs to monitor (Andrade and Cizek 2010). Obviously it takes time and rehearsal for students to learn to answer the aforementioned questions. Creating multiple opportunities for students to, for example, articulate where they are in the design process helps the student to learn how to see both their own work and the work of others (Andrade and Cizek 2010; Nicol and Macfarlane-Dick 2006). It provides them with input to reflect on why a design activity they have undertaken was unsuccessful or successful. Mismatches between students' intentions and their actual work are very useful for students and provide them with input for reflection. It also supports students in stating where they would like to go to with their design process and how to realize it. A frequent source of input is the mismatch between students' ideas on what they have done or are still doing and what the work demonstrates. Coaches should help students to learn to see these mismatches (Sawyer 2017). So, coaching sessions can be structured by exploring and co-constructing where students are, where they would like to go and how they will get there with respect to design processes. In the ideal case, students are able to answer these questions for themselves. To make coaching effective, students should answer these questions for themselves when preparing the coach meetings.

\section{Coaching goal 1.4: professional identity development}

Proposition 1.4.1 Coaching requires challenging students to explore their own Professional Identity and (in the long run) develop insight into the range of existing design conceptualizations.

Learning to design encompasses more than just developing knowledge, skills, and competencies. It is also about developing a professional identity (PI) (Tracey and Hutchinson 2016). Students' PI has been mentioned in this respect (Lawson and Dorst 2013). Professional identity development (PID) is about how a student views himself as a future professional designer. PID requires the integration of one's personal traits, motives, competencies, values, morals, beliefs, and attributes with the norms of the profession and technical knowledge (Kunrath 2019; Van Diggelen and Morgan 2017). It includes the awareness and understanding of the self in the design sphere and what is expected within that space (Sawyer 2017). Students must learn to see who they are as a designer and how their professional identity affects their professional work (Tracey and Hutchinson 2016, 2018).

Explicitly paying attention to the PID of students is important because actions in the design process are reflected by it. Developing self-knowledge will help improve future designing. To become successful in integrating new design approaches the students have to become aware of their own conception of design and how it varies from others. It is often the designer who generates, selects, tests, and refines ideas in order to better understand the problem and to develop solutions. Thus, it is important for designers to understand how they influence this process via their personal experiences, beliefs and actions, particularly as they relate to the affective aspects of the design process (Hutchinson and Tracey 2015).

A coach should play an active role in making the student understand how elements of his/her professional identity affect the design process. It will stimulate deep learning when students learn to see deeper levels of their behavior and link their design behavior and decisions to it. Reflection leading to deep learning will increase the likelihood of transfer of knowledge and skills (Korthagen and Vasalos 2005). Explicitly addressing the PI will help 
students become aware of their unique characteristics and how to distinguish themselves from colleagues (Van Diggelen and Bruns 2015). It will build confidence and help to foster professional development (Kunrath 2019). Having self-knowledge and being aware of their PI provides students with stability in the uncertain, ambiguous and open design challenge and process (Kunrath 2019; Tracey and Hutchinson 2016, 2018). But above all, coaches can use this focus to make students aware of the professional practice and their profession. It is the focus to make the learning thoroughly authentic.

Proposition 1.4.2 Coaching requires challenging students to explore the PI of the coach and (in the long run) develop insight into the range of existing design conceptualizations.

The observations and interviews with teachers in the qualitative study demonstrated that the implicit design conceptualizations and more in general a coach his PI has a strong influence on how he/she coaches. How a coach conceptualizes design and designing will strongly influence what he sees as important in learning, what he expects from his students, what he sees as a good design process and where he will focus on in the coaching. Next to the beliefs of the coach, also his values, norms, competency profile, and specific expertise strongly influence his coaching (Van Diggelen and Morgan 2017). The observations and interviews with coaches in the qualitative study made clear that The PI of the coach will manifest itself in coaching. Coaching, then, is a reflection of the PI of the coach. Explicating the PI of a coach will likely reduce its implicit impact on students' learning and likely keep the learning more discovery-oriented.

The challenge for a coach is to make his PI explicit and the subject of student exploration without unnecessary influencing how students frame design challenges, go through design processes and create deliverables. Challenging students to explore the PI of the coach will help students to better read coaching interventions, intentions behind coaching and will help them to gain more profit from the specific expertise of the coach (Winstone et al. 2017a, b). It will also help students to develop their own PI, expand their design repertoire and will be supportive of them in dealing with the complexity and ambiguity of ill-defined problems and professional practice. Finally, the increased awareness and understanding of different design conceptualizations may be beneficial for students in teamwork requiring multidisciplinary collaboration and for fueling innovation. Cross-disciplinary collaboration and innovation will require the understanding of variations in the ways people experience and make meaning around design. Understanding the design conceptualizations of the others will likely increase opportunities for innovation.

Proposition 1.4.3 Coaching requires relating design activities and processes to personal and/or professional experiences or images of practices.

Learning to design is partly a matter of learning by doing and gaining experience. As such, it is not only about integrating theoretical/formal knowledge in the design process but also about activating tacit knowledge (Sadler 2010; Wong and Radcliffe 2000). This tacit knowledge encapsulated in experiences needs to be activated to make it possible for students to articulate knowledge and experience learning (Sadler 2010). Coaching interventions only land when there is formal knowledge available to build upon or when a student has a vivid image of an important experience (Black and 
Wiliam 2009; Hattie and Timperley 2007; Van Diggelen et al. 2013). Addressing personal and professional experiences or images of practice is also a way to make students motivated and see the relevance of, for example, DBL projects in general.

A problem students frequently encounter in DBL is, what we call the transparency challenge. In DBL where students work on open and ill-defined problems, it is often the problem that students don't know what teachers expect of them, what the intentions of teachers are and where they will be assessed upon (Sawyer 2017, 2018; Schön 1987). This is partly related to the fact that students need to develop skills in order to see and recognize good work, find out what is needed and how to get there. It is the curse of competence where students and coaches involved in DBL need to deal with (Schön 1983).

\section{Main category 2.0: coaching environment}

In order to open up, think freely and share their thoughts with both fellow students and the coach it is important that students perceive the environment as safe (Carless 2013; Van Diggelen et al. 2013). Furthermore, if students perceive the environment as stimulating they will likely be more actively engaged, try to experiment more and it makes it easier for them to learn from failures (Sawyer 2017).

Proposition 2.1 Coaching requires a safe and stimulating environment.

Students work in project teams. In these projects, students are supposed to collaborate and strive for realizing as a team more than the sum of the contribution of all the individual members. The dialogue between the members of the group and peer feedback exchanges are important in this respect (Evans 2013). Dialogue and peer feedback can improve students' reflection and lead to students interacting with different conceptualizations (Liu and Carless 2006; Nicol et al. 2014). However, the observations, reflections in on the wikipage and written reflections of students analyzed during the qualitative study demonstrated that, for various reasons, it can be difficult to create a dialogue, and ask for and provide honest and constructive feedback to fellow student members of the teams. At large scale universities, students often do not know each other before the start of the project which makes that relationships need to be established during the DBL project.

\section{Main category 3.0: coaching dialogue}

Proposition 3.1 Coaching requires contributing to students coaching literacy.

One of the main barriers to effective coaching is low coaching literacy of students (Carless and Boud 2018). Students need to learn to take up to make sense of the idea, message and intentions of coaching interventions and information revealed by it and to actually use it. First, students need to learn to recognize the value of coaching and understand their active role in its processes. It is important to address students' conceptions which may, for example, often involve feedback as telling or being informed by an expert ignoring their responsibility and active role in it (Carless and Boud 2018; McLean et al. 2015). Secondly, students need to develop the capability 
to make decisions about the quality of work of oneself and others (Carless and Boud 2018; Tai et al. 2018). This requires offering extensive opportunities for self-evaluation and involving others for comparing views. In time, it helps students to become more accurate in judging the quality of their own work (Boud et al. 2013). Thirdly, students need to learn to manage their affective responses. Students may, for example, tend to respond defensively to coaching when it is (perceived as) critical (Carless and Boud 2018; Robinson et al. 2013). In these situations, it may provoke negative feelings, emotions, and attitudes and may pose threats to the students' identity. How students actually give meaning and affectively respond to it is strongly influenced by their relationship with the coach and their fellow-team members (Esterhazy and Damsa 2017). In a trusting environment, students are more likely to develop the confidence and faith to reveal what they do not fully understand (Carless 2013). Fourthly, coaching literacy requires students to act upon coaching interventions (Carless and Boud 2018; Sutton 2012). To do so, students need to engage actively in making sense of information and use it to inform their later work (Boud and Molloy 2013). Too often, this step is ignored in coaching and for various reasons, it is not checked whether the feedback is actually used. So, students need to learn to see themselves as agents of their own change and develop identities as pro-active learners (Boud and Molloy 2013).

\section{Proposition 3.2 Coaching requires stimulating dialogue amongst the project team.}

Students participating in our case study often were enrolled in different majors. Consequently, they come with their own but different frames of reference to the meetings. The students have another competency profile, speak another disciplinary language and likely have different thoughts and beliefs about the design process and outcomes. The observations in the qualitative study demonstrated that coaches can help to facilitate and start the dialogue by emphasizing it in their coaching, by actively intervening to realize the conditions for this kind of coaching and by facilitating a dialogue between the students in the meetings (Bakker et al. 2015). This will help to develop a shared understanding.

A successful group is thinking together as a group and its members identify with the dialogue between group members and not so much with themselves or the group (Mercer et al. 2013). In such a group, there is an opportunity for dialogue characterized by openness and a multiplicity of voices. It is the mutual exploration and meaning-making that is deemed important and not the ownership of ideas (Mercer et al. 2013). These dialogues reflect and build on the students' PI. A useful strategy in this respect might be the formulation of group goals. It helps students to think and discuss with their teammembers, makes them committed and helps them to identify themselves with the others.

Proposition 3.3 Coaching requires all stakeholders to approach it as a continuous dialogue.

The idea is that dialogue is crucial for successful learning in DBL (Merry et al. 2013). A successful dialogue, however, asks for an intentional arrangement of the coaching situation and context. Effective interaction and dialogue only take place within a context of mutual understanding (Boud and Molloy 2013). In such a context, students are able to imagine, understand and relate to the frame of reference of the coach and the coach to theirs. It is also necessary that both the students and the teachers interact in the 
context of a shared frame of reference (Schön 1983). Either, these conditions are established before the conversation or realized during the conversation.

A dialogue actually consists of a continuous feedback loop (Carless 2019). This loop provides teachers the opportunity to check whether the intervention has the intended effect or not (Van Diggelen et al. 2013). A coach is, for example, able to check whether or not a hint is taken, a question directs the attention of the student in an intended way, generates the proper knowledge, results in active engagement of the student or fosters thinking. Actually, this kind of interventions fulfills the role of formative assessment wherein evidence is collected to determine to what extent the intended effects are realized and why so (Black and Wiliam 2009; Van den Pol et al. 2010). If not, the information can be used to re-intervene. A continuous loop is also of use to students. Such a loop provides students with the opportunity to respond to the coaching intervention, to ask for clarification, to comment on it, discuss it, elaborate on it, nuance it or takes the conversation in a different direction if a student feels the need for different input.

Proposition 3.4 Coaching requires a coach to deliberately make use of coaching interventions.

The qualitative study learned us that most coaches intuitively use different coaching interventions. A coach can, for example, provide feedback, ask questions, model behavior, use articulation interventions, provide instruction, provide tips or tricks, provocative interventions or apply improvisation interventions (Collins et al. 1989). These interventions range from more supportive (e.g. instruction and modeling behavior) to more challenging (why questions or provocative interventions) (Adams et al. 2016; Thomas 2000; Van Diggelen et al. 2013). It is important that the coach has a broad skill-set of interventions, is able to make deliberate use of it and varies with them.

Proposition 3.5 Coaching requires a coach to adequately apply conversation skills.

Coaching can be seen as a communication process where coaches interact and have a dialogue with their students (Bakker et al. 2015). The observations in the qualitative study demonstrated that conversation techniques are inherent in coaching though coaches may not be aware of them as being conversation techniques. It also became apparent that many of these skills are intuitively applied, e.g., summarizing, active listening, asking open and closed questions, parroting, and so on. In our qualitative study, we learned that coaches could benefit from learning the ins and outs of this kind of techniques. Possessing these skills can really add and contribute to the quality of the dialogue. Asking a series of closed questions can, for example, help students to open up. Providing a summary can help to provide structure to the dialogue. Moreover, active listening can demonstrate the genuine interest of the coach, make the students feel safe, open up, contribute to motivation and stimulate students to continue thinking or speaking. Parroting, for example, can also help to provide structure, to interrupt or to make someone take, or to provide turns. These are just a few examples of all options conversation skills provide. Considering the importance of conversation skills we were surprised that this kind of skills is hardly addressed in the consulted literature. Especially, because these techniques can be easily trained in, for example, role plays or simulation settings. 


\section{Conclusions}

The research question addressed in this paper is: What does good coaching in DBL entail? This question was answered using a grounded theory approach wherein we constantly compared data from a qualitative study and data from a literature review to formulate a higherorder theory on coaching in DBL and to formulate practical propositions. This higher-order theory and the practical propositions fulfill three functions.

A first function of the higher-order theory is to explicate what can be seen as good coaching in DBL. To compose the higher-order theory we attempted to bridge (diverse) theoretical and practical perspectives on good coaching in DBL. This was the main objective of this study. The result of this study is a theoretical model on coaching in DBL consisting of three main categories (with seventeen themes): (1) goal-directed coaching (with the categories: designing; design thinking and process; self-regulation, and professional identity); (2) the coaching environment, and (3) the coaching dialogue. We formulated thirteen practical propositions. The theoretical model and practical propositions can be seen as a starting point for developing a research-driven knowledge base on what good coaching in DBL entails. As such, the theoretical model and proposition function to inform and direct follow-up research on coaching in DBL. The propositions, for example, can be seen as hypotheses that can be tested.

The theoretical model and propositions on coaching also serve a critical function. The propositions can be seen as a set of propositions which coaches and their colleagues can use to formatively evaluate their coaching practices. Educational developers could use the propositions for evaluation purposes and use the underlying theoretical model to make evidence-informed decisions. However, it should be noted that what counts as good coaching is relative. It depends, for example, on the objectives of coaching, on the specific perspective of the actor involved performing the evaluation, and on the immediate demands of the student and the situation.

A final function of the theoretical model and propositions is to provide an overview of factors involved in coaching in DBL. It becomes immediately apparent that coaching in DBL is a very complex skill (Hmelo-Silver et al. 2019). Coaches need to be skilled improvisers, able to respond in-the-moment to unexpected contingencies and unpredictable interactions that occur in DBL (Adams et al. 2016). The theoretical model and propositions allow for a broad range of acceptable ways of coaching in DBL. They are composed in a continuous dialogue between both practical and theoretical perspectives on good coaching while using a variety of data-collection methods. The model and propositions illustrate that what can be seen as good coaching is a holistic, dialogical and therefore communicative and social process that, as we argue, should emphasize the professional identity (development) of both the coach and students and equip students to learn from their coaches.

Acknowledgements The authors are grateful for the participation and contribution of the coaches involved in the case study and would like to thank Dr. Ir. Joep (J.W.) Frens for his valuable contributions to earlier versions of the manuscript.

Funding This work was supported by the 4TU/e Centre of Engineering Education and the deans of the Bachelor College and Graduate School of the Eindhoven University of Technology, the Netherlands.

\section{Compliance with ethical standards}

Conflict of interest The authors declare no conflict of interest. 
Open Access This article is distributed under the terms of the Creative Commons Attribution 4.0 International License (http://creativecommons.org/licenses/by/4.0/), which permits unrestricted use, distribution, and reproduction in any medium, provided you give appropriate credit to the original author(s) and the source, provide a link to the Creative Commons license, and indicate if changes were made.

\section{References}

Adams, R. S., Forin, T., Chua, M., \& Radcliffe, D. (2016). Characterizing the work of coaching during design reviews. Design Studies, 45, 30-67.

Adams, R. S., Turns, J., \& Atman, C. (2003). Educating effective engineering designers: The role of reflective practice. Design Studies, 24(3), 275-294.

Akkerman, S., Admiraal, W., Brekelmans, M., \& Oost, H. (2008). Auditing quality of research in social sciences. Quality \& Quantity, 42(2), 257-274.

Andrade, H., \& Cizek, G. J. (Eds.). (2010). Handbook of formative assessment. London: Routledge.

Bakker, A., Smit, J., \& Wegerif, R. (2015). Scaffolding and dialogic teaching in mathematics education: Introduction and review. ZDM Mathematics Education, 47(7), 1047-1065.

Barron, B. J., Schwartz, D. L., Vye, N. J., Moore, A., Petrosino, A., Zech, L., et al. (1998). Doing with understanding: Lessons from research on problem-and project-based learning. Journal of the Learning Sciences, 7(3-4), 271-311.

Black, P., \& Wiliam, D. (2009). Developing the theory of formative assessment. Educational Assessment, Evaluation and Accountability (Formerly: Journal of Personnel Evaluation in Education), 21(1), 5.

Boud, D., \& Molloy, E. (2013). Rethinking models of feedback for learning: the challenge of design. Assessment and Evaluation in Higher Education, 38(6), 698-712.

Boud, D., Lawson, R., \& Thompson, D. G. (2013). Does student engagement in self-assessment calibrate their judgement over time? Assessment \& Evaluation in Higher Education, 38(8), 941-956.

Brodeur, D. R., Young, P. W., \& Blair, K. B. (2002). Problem-based learning in aerospace engineering education. In Proceedings of the 2002 American society for engineering education annual conference and exposition, Montreal, Canada (pp. 16-19).

Bryant, A., \& Charmaz, K. (2007). The SAGE handbook of grounded theory. London: SAGE Publications Ltd.

Carless, D. (2013). Trust and its role in facilitating dialogic feedback. In D. Boud \& E. Molley (Eds.), Feedback in higher and professional education (pp. 100-113). Abingdon: Routledge.

Carless, D. (2019). Feedback loops and the longer-term: towards feedback spirals. Assessment \& Evaluation in Higher Education, 44(5), 705-714.

Carless, D., \& Boud, D. (2018). The development of student feedback literacy: Enabling the uptake of feedback. Assessment and Evaluation in Higher Education, 43, 1315-1325.

Charmaz, K. (2006). Constructing grounded theory: A practical guide through qualitative analysis. London: Sage Publications.

Clark, I. (2012). Formative assessment: Assessment is for self-regulated learning. Educational Psychology Review, 24(2), 205-249.

Collins, A., Brown, J. S., Newman, S. E., \& Resnick, L. B. (1989). Cognitive apprenticeship: Teaching the craft of reading, writing, and mathematics. In L. B. Resnick (Ed.), Knowing, learning, and instruction: Essays in honor of Robert Glaser (pp. 453-494). Hillsdale: Lawrence Erlbaum Associates.

De Graaf, E., \& Kolmos, A. (2003). Characteristics of problem-based learning. International Journal of Engineering Education, 19(5), 657-662.

Dunne, C. (2011). The place of the literature review in grounded theory research. International Journal of Social Research Methodology, 14(2), 111-124.

Dym, C. L., Agogino, A. M., Eris, O., Frey, D. D., \& Leifer, L. J. (2005). Engineering design thinking, teaching, and learning. Journal of Engineering Education, 94(1), 103-120.

Edström, K., \& Kolmos, A. (2014). PBL and CDIO: Complementary models for engineering education development. European Journal of Engineering Education, 39(5), 539-555.

Esterhazy, R., \& Damşa, C. (2017). Unpacking the feedback process: An analysis of undergraduate students' interactional meaning-making of feedback comments. Studies in Higher Education, 44, 1-15.

Evans, C. (2013). Making sense of assessment feedback in higher education. Review of Educational Research, 83(1), 70-120.

Glaser, B. G., \& Strauss, A. L. (2017). Discovery of grounded theory: Strategies for qualitative research. New York: Routledge. 
Gomez Puente, S. M., van Eijck, M., \& Jochems, W. (2013). A sampled literature review of design-based learning approaches: A search for key characteristics. International Journal of Technology and Design Education, 23(3), 717-732.

Hattie, J., \& Timperley, H. (2007). The power of feedback. Review of Educational Research, 77(1), 81-112.

Henderson, M., Ryan, T., \& Phillips, M. (2019). The challenges of feedback in higher education. Assessment \& Evaluation in Higher Education, 44, 1-16.

Hinson, D. (2007). Design as research: Learning from doing in the design-build studio. Journal of Architectural Education, 61(1), 23-26.

Hmelo-Silver, C. E. (2004). Problem-based learning: What and how do students learn? Educational Psychology Review, 16(3), 235-266.

Hmelo-Silver, C. E., \& Barrows, H. S. (2006). Goals and strategies of a problem-based learning facilitator. Interdisciplinary Journal of Problem-Based Learning, 1(1), 4.

Hmelo-Silver, C. E., Bridges, S. M., \& McKeown, J. M. (2019). Facilitating problem-based learning. In M. Moallem, W. Hung, \& N. Dabbagh (Eds.), The Wiley handbook of problem-based learning (pp. 297-319). New York: Wiley.

Hutchinson, A., \& Tracey, M. W. (2015). Design ideas, reflection, and professional identity: How graduate students explore the idea generation process. Instructional Science, 43(5), 527-544.

Korthagen, F., \& Vasalos, A. (2005). Levels in reflection: Core reflection as a means to enhance professional growth. Teachers and Teaching, 11(1), 47-71.

Kunrath, K. (2019). Designer's professional identity: understanding composition, development, and perceptions. Ph.D. thesis, Technical University of Danmark.

Lawson, B., \& Dorst, K. (2013). Design expertise. London: Routledge.

Liu, N. F., \& Carless, D. (2006). Peer feedback: The learning element of peer assessment. Teaching in Higher Education, 11(3), 279-290.

Lousberg, L., Rooij, R., Jansen, S., van Dooren, E., Heintz, J., \& van der Zaag, E. (2019). Reflection in design education. International Journal of Technology and Design Education, 28, 1-13.

McDonnell, J. (2016). Scaffolding practices: A study of design practitioner engagement in design education. Design Studies, 45, 9-29.

McLean, A. J., Bond, C. H., \& Nicholson, H. D. (2015). An anatomy of feedback: A phenomenographic investigation of undergraduate students' conceptions of feedback. Studies in Higher Education, 40(5), 921-932.

Mercer, N., Wegerif, R., \& Dawes, K. (2013). Children's talk and the development of reasoning in the classroom. British Educational Research Journal, 25(1), 95-111.

Merry, S., Price, M., Carless, C., \& Taras, T. (Eds.). (2013). Reconceptualising feedback in higher education. Abingdon: Routledge.

Miller, G. E. (1990). The assessment of clinical skills/competence/performance. Academic Medicine, 65, 63-67.

Nicol, D. J., \& Macfarlane-Dick, D. (2006). Formative assessment and self-regulated learning: A model and seven principles of good feedback practice. Studies in Higher Education, 31(2), 199-218.

Nicol, D., Thomson, A., \& Breslin, C. (2014). Rethinking feedback practices in higher education: A peer review perspective. Assessment \& Evaluation in Higher Education, 39(1), 102-122.

Price, M., Handley, K., Millar, J., \& O'donovan, B. (2010). Feedback: All that effort, but what is the effect? Assessment \& Evaluation in Higher Education, 35(3), 277-289.

Prince, M. J., \& Felder, R. M. (2006). Inductive teaching and learning methods: Definitions, comparisons, and research bases. Journal of Engineering Education, 95(2), 123-138.

Ramaprasad, A. (1983). On the definition of feedback. Behavioral Science, 28(1), 4-13.

Razzouk, R., \& Shute, V. (2012). What is design thinking and why is it important? Review of Educational Research, 82(3), 330-348.

Robinson, S., Pope, D., \& Holyoak, L. (2013). Can we meet their expectations? Experiences and perceptions of feedback in first-year undergraduate students. Assessment \& Evaluation in Higher Education, $38(3), 260-272$.

Sadler, D. R. (1989). Formative assessment and the design of instructional systems. Instructional Science, $18(2), 119-144$.

Sadler, D. R. (2010). Beyond feedback: Developing student capability in complex appraisal. Assessment and Evaluation in Higher Education, 35(5), 535-550.

Savin-Baden, M. (2003). Facilitating problem-based learning. Maidenhead: McGraw-Hill Education.

Sawyer, K. (2015). A call to action: The challenges of creative teaching and learning. Teachers College Record, 117(10), 1-34.

Sawyer, R. K. (2017). Teaching creativity in art and design studio classes: A systematic literature review. Educational Research Review, 22, 99-113. 
Sawyer, K. (2018). Teaching and learning how to create in the schools of design and art. Journal of the Learning Sciences, 27, 137-181.

Schank, R. C., Berman, T. R., \& Macpherson, K. A. (1999). Learning by doing. Instructional-design theories and models: A new paradigm of instructional theory, 2(2), 161-181.

Schön, D. (1983). The reflective practitioner: How professionals think in action. New York: Basic Books.

Schön, D. A. (1987). Educating the reflective practitioner. San Francisco: Jossey-Bas.

Sutton, P. (2012). Conceptualizing feedback literacy: Knowing, being, and acting. Innovations in Education and Teaching International, 49(1), 31-40.

Tai, J., Ajjawi, R., Boud, D., Dawson, P., \& Panadero, E. (2018). Developing evaluative judgement: Enabling students to make decisions about the quality of work. Higher Education, 76(3), 467-481.

Thomas, J. W. (2000). A review of research on project-based learning. http://www.bobpearlman.org/BestP ractices/PBLResearch.pdf. Accessed March 2018.

Tracey, M. W., \& Hutchinson, A. (2016). Uncertainty, reflection, and designer identity development. Design Studies, 42, 86-109.

Tracey, M. W., \& Hutchinson, A. (2018). Reflection and professional identity development in design education. International Journal of Technology and Design Education, 28(1), 263-285.

Van den Pol, J., Volman, M., \& Beishuizen, J. (2010). Scaffolding in teacher-student interaction: A decade of research. Educational Psychology Review, 22(3), 271-296.

Van Diggelen, M. R., \& Bruns, M. (2015). Towards a vision for industrial design education. In Proceedings of the 43rd SEFI annual conference, Orléans.

Van Diggelen, M. R., \& Morgan, C. M. (2017). Studying teacher coaching: How was it intended, implemented, and perceived? Eindhoven: Technical University Eindhoven.

Van Diggelen, M. R., den Brok, P. J., \& Beijaard. D. (2013). Teachers' use of a self-assessment procedure: The role of criteria, standards, feedback, and reflection. Teachers and Teaching, 19(2), 115-134.

Van Dooren, E., Boshuizen, E., Van Merriënboer, J., Asselbergs, T., \& Van Dorst, M. (2014). Making explicit in design education: Generic elements in the design process. International Journal of Technology and Design Education, 24(1), 53-71.

van Dooren, E. J. G. C., Van Merriënboer, J., Boshuizen, H. P. A., Van Dorst, M., \& Asselbergs, M. F. (2018). Architectural design education: In varietate unitas. International Journal of Technology and Design Education, 28(2), 431-449.

Waks, L. J. (2001). Donald Schon's philosophy of design and design education. International Journal of Technology and Design Education, 11(1), 37-51.

Winstone, N. E., Nash, R. A., Parker, M., \& Rowntree, J. (2017a). Supporting learners' agentic engagement with feedback: A systematic review and a taxonomy of recipience processes. Educational Psychologist, 52(1), 17-37.

Winstone, N. E., Nash, R. A., Rowntree, J., \& Parker, M. (2017b). 'It'd be useful, but I wouldn't use it': Barriers to university students' feedback seeking and recipience. Studies in Higher Education, 42(11), 2026-2041.

Wong, W. L. P., \& Radcliffe, D. F. (2000). The tacit nature of design knowledge. Technology Analysis \& Strategic Management, 12(4), 493-512.

Publisher's Note Springer Nature remains neutral with regard to jurisdictional claims in published maps and institutional affiliations. 